\title{
"Effect of Night Shift on Personal Health and Other Factors of Nurses at Rajshahi Medical Collage Hospital, Rajshahi, Bangladesh"
}

\author{
Tanzina Islam ${ }^{1 *}$, Hasibul Hasan ${ }^{2}$, Sefali Khatun ${ }^{3}$
}

${ }^{1}$ RN, Department of Orthopedic Surgery, Rajshahi Medical Collage Hospital, Rajshahi, Bangladesh

${ }^{2}$ MNSFT, Islamic University of Bangladesh

${ }^{3}$ Nursing Instructor, Rajshahi Nursing College, Rajshahi, Bangladesh

DOI: $10.36347 /$ sjams.2021.v09i03.020

| Received: 21.02.2021 | Accepted: 08.03.2021 | Published: 11.03.2021

*Corresponding author: Tanzina Islam

This descriptive exploratory study was conducted to describe the night shift related health problems and other factor of the nurses working at Rajshahi Medical College Hospital, Rajshahi, Bangladesh. A convenience sample of nurses working that Medical wards nurses had a significant difference on sufficient sleep, and interpersonal at specific units $(\mathrm{N}=50)$ were studied using a structured questionnaire developed that describe the effect of night shift among nurses working at Rajshahi Medical College Hospital Rajshahi, Bangladesh. The findings showed that female conflicts. In addition, the results indicated that nurses experience health problem and their work performance affected by the night shift. The study findings indicated that night shift affects some specific ward nurses well-being. Consequently, this study emphasizes and urges the need to design proper nursing manager interventions that help nurses to improve quality care of nursing. It was obviously clear that the nurses faced physiological problems and psychological hazards at night shift working at Rajshahi Medical College Hospital Rajshahi, Bangladesh.

Keywords: Night Shift, Effect, Personal Health, Factors of Nurses.

Copyright $\odot 2021$ The Author(s): This is an open-access article distributed under the terms of the Creative Commons Attribution 4.0 International License (CC BY-NC 4.0) which permits unrestricted use, distribution, and reproduction in any medium for non-commercial use provided the original author and source are credited.

\section{INTRODUCTION}

The effects of night shift work include decreased psychosocial and physiological health of the individual, as well as decreased job performance. The development of a cost-effective, easyto-use tool for detection of chronic stress accumulation in individual nurses would allow for recognition of potential harm to the nurse and the patients they encounter [1]. Nurses as health care providers are obliged to work during the day and during the night to care for the needs of sick people. Night shift term defined as work performed after 8pm and before $8 \mathrm{am}$ the next day, therefore, the activity at night will be out of phase with the body temperature and other coupled rhythms. In addition, because individual biological rhythms, re-entrain to a time shift at different rates, each time the work schedule rotates, for a period of time after the time shift, the circadian system will be in a desynchronized state [2]. This disorientation can lead health, psychosocial effect such as feeling of fatigue and disorientation. Conceptual definition of effect is a change from original status. This study defines it as the change in health, psychological, and social status of nurses after working at night shift. The literature revealed that there is various effect of night shift on workers, night work have implications for the entire living sphere of mankind, thus health hazards and stresses of work itself, as well as intervening factors from outside the working life may influence, and impair the state of health. Literature agrees that the effect of night is due to disruptions in circadian rhythms. They also state that these effects are associated with phase shifting in sleep and wakefulness cycles, and cause interferences with daily routine at work and in family and social life [3]. Effect of night on nurses particularly highlighted, but few studies examine that effect on intensive care nurses and the consequences on critical patient and quality of care. Sleep is one of the main reasons why irregular hours cause ailments and disorders. Extended waking leads to tiredness and reduced functional capacity. The effects are initially noticeable mostly if the individual is exposed for longer periods to a monotonous situation. After the first 24 hours without sleep, the functional capacity may be halved and after two sleepless days, the functional capacity is falling an asleep is ever present.

\section{OBJECTIVES OF THE STUDY}

\section{General objective}

1. The study will be carried out with a view to assess the effect of night shift in personal health and other 
factor of nurses at Rajshahi Medical College Hospital Rajshahi, Bangladesh.

\section{Specific Objectives}

1. To describe the night shift related problems on nurses and to evaluate the impact of these on the health and well-being.

2. To provide applicable recommendation to decrease stress produced by working conditions, and promote the best patient care.

3. To help both nurses and administrators to understand some of the underlying night shift related health problem and other factors on nurses, and their impact on nurse's life, clinical practices.

\section{REVIEW OF LITERATURE}

The effects of shift work stress across various occupations, on shift work stress specific to the field of nursing, and on the mechanisms by which stress can contribute to disease. Information from a variety of occupations outside of nursing have already studied numerous adverse health effects affiliated with shift work stress and will be reviewed here. The WHR tool developed to evaluate stress exposure and risk for health disorders requires attention and will also be discussed. The Neumann Systems Model, and more specifically Primary Prevention as Intervention, is the theoretical framework upon which this study was based and as such will be explored further in this section. Shift schedules refer to the assignment of workers to a particular shift and time allocated to each of the shift pattern [4]. Study finding may also provide a knowledge base for further research that addressed after studying all aspects of nurses work shift and its relationship with other factors in the clinical and other world. Moreover Lushington and Dawson [5, 6], stated that Night shift has physical and social effects on the life of an individual including nurses, the long hours that they work interfere with their health and their safety. Night work can even be more negative impact for female nurses who also have family responsibilities such as pregnancy and child rearing. For nurses these negative effects have consequences not just for the individual, but also for the workplace, as decreased alertness and reduced job performance could, endanger human lives [7].

\section{Materials and Methods}

The descriptive correlational design was used to explore the nurses' knowledge and attitude at nursing due to effect of night shift on personal health and other factor of nurses at Rajshahi Medical College Hospital, Rajshahi, Bangladesh. In addition, the relationships among nurses' knowledge, attitudes about effect of night shift were examined. This research design is of descriptive exploratory design, it describes the Phenomenon as it exists in the current time; it is more practical in the implementation, economical in cost, and easy to manage. The study utilizes the data to recognize the level of knowledge and attitudes of the nurse toward night shift work, therefore the study is designed to describe the effect of night shift on nurses.

Study place and duration: The study populations were the 50 nurses of the Rajshahi Nursing College, Rajshahi Rajshahi, Bangladesh. The study duration is 6 months. The study was carried out from November 2014 to April 2015.

Research methodology: In research methodology describes the design of the study, population, setting and sample, instrumentation, data collection procedure, and data analysis.

Effect of Night Shift on Personal Health and Other Factor of Nurses at Their Working Place: This questionnaire was designed to assess the nurse's word, physical and social conditions regarding problem of night shift. It was composed of 13 multiple choice questions and 10-Yes/No questions which had been modified. In order to meet the demand for an improved efficiency of dealing with the extended hours of work in some industries, there has been an increasing drive towards the use of shift- workers. The main purpose of this descriptive study was to identify the effect of night shift on personal health and other factor on nurses at Rajshahi medical college hospital Rajshahi, Bangladesh.

Ethical clearance: At first proposal was send to the Director and nursing superintendent of Rajshahi Medical College Hospital, Rajshahi, Bangladesh. Informed consent will be obtained from the institution authorities and subjects. Privacy confidentiality and anonymity will be quarded scientific objectivity of the study will be maintained with honesty and impartiality.

\section{RESULTS}

The results regarding the effect of night shift on personal health and other factor of nurses at Rajshahi Medical College Hospital, Rajshahi, Bangladesh has been presented in Tables 1-7 and Figures 1-8. Subjects' characteristics regarding demographic information about nurses. Fifty questionnaires were distributed among nurses working at Rajshahi Medical College Hospital. Table-1-7 showed that regarding that age of the nurses, the most of the respondents age within 26-30 years $6(12 \%), 31-35$ year $15(30 \%), 36-40$ year $18(36 \%)$ the lowest group respondent age within 41-45 year25 $(50 \%)$.The gender of the respondents are the height number are $46(92 \%)$ female and the lowest number are $2(4 \%)$ male. The marital status of the total respondents are 50, most of the (48) $96 \%$ are married, 2 (4\%) single and $0 \%$ widow. The total religion of the respondents are 50, most of them were Muslim 35 (70) $\%$, Hindu11 (22\%) and Christian 4(8\%) Buddist 0\% .Among 50 nurses Professional qualification of the respondents(38) 76\% Diploma in Nursing and Midwifery in Nursing, (12) $24 \%$ B.Sc. in Nursing and 
Tanzina Islam et al; Sch J App Med Sci, Mar, 2021; 9(3): 393-397

MPH-3 (6\%).Among 50 nurses Academic qualification of the respondent S.S.C-45 (90\%), H.S.C-5 (10\%), B.Sc./B.A-1 (2\%).B. .Masers $0 \%$ and other $0 \%$ Specialization course on ICU nursing \& management 8 (16\%) and CCU nursing \& management.

Table-1: Age distribution of the respondents.

\begin{tabular}{|l|l|l|l|}
\hline Variable & Range & Number & Percentage \\
\hline \multirow{4}{*}{ Age } & $26-30$ years & 6 & $12.0 \%$ \\
\cline { 2 - 4 } & $31-35 y e a r s$ & 15 & $30.0 \%$ \\
\cline { 2 - 4 } & $36-40$ years & 18 & $36.0 \%$ \\
\cline { 2 - 4 } & 41-45years & 25 & $50.0 \%$ \\
\hline
\end{tabular}

Table no-1 shows that the majority of the respondents $50 \%$ were in age group of 41-45 years smallest number of the respondents $12 \%$ were bellow $30,36 \%$ respondent's were in age group of 36-40 years, and $30 \%$ respondent's were in age group of $31-35$ years.

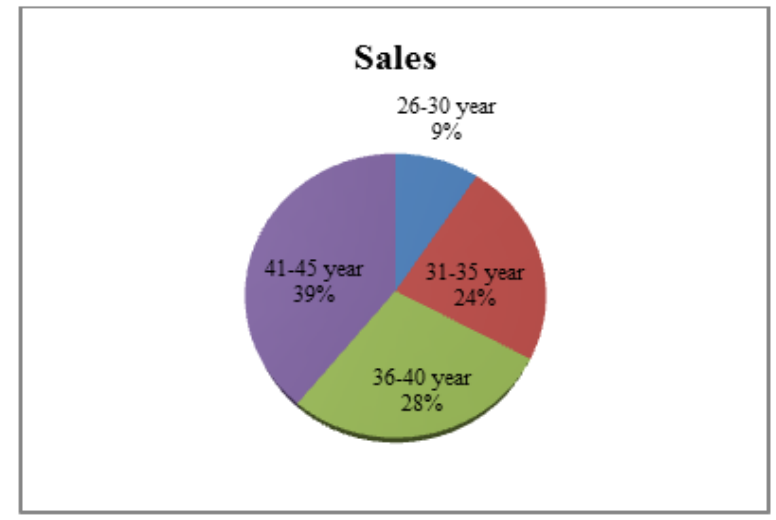

Fig-1: Sales distribution of patient's age

Table-2: Gender distribution of the respondents

\begin{tabular}{|l|l|l|l|}
\hline variable & Parameter & Number & Percentage \\
\hline \multirow{2}{*}{ Gender } & Male & 3 & $6.0 \%$ \\
\cline { 2 - 4 } & Female & 47 & $94.0 \%$ \\
\hline
\end{tabular}

Table-2shows that most of the nurse respondents (94\%) were female \&only $6 \%$ were male. The result showed majority of female nurses working in the Rajshahi Medical College Hospital.

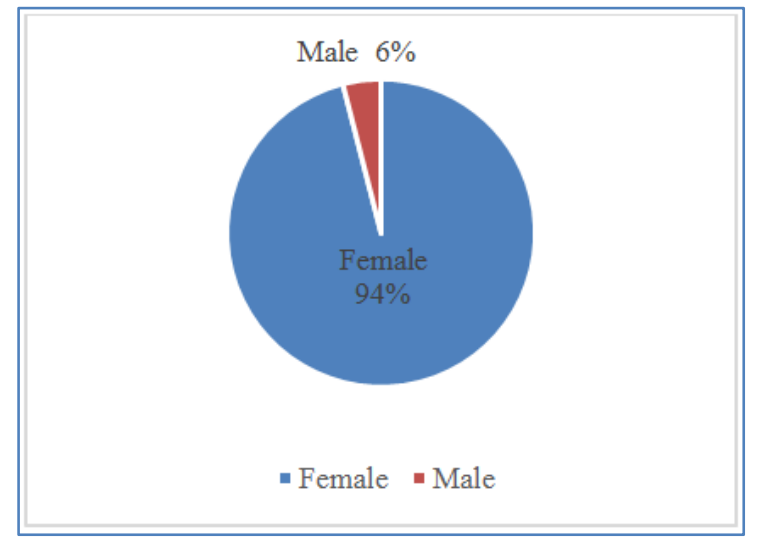

Fig-2: Gender distribution of the respondents
Table-3: Marital status of the respondents.

\begin{tabular}{|l|l|l|l|}
\hline variable & Parameter & Number & Percentage \\
\hline \multirow{3}{*}{$\begin{array}{l}\text { Marital } \\
\text { status }\end{array}$} & Single & 2 & 4.0 \\
\cline { 2 - 4 } & Married & 48 & 96.0 \\
\cline { 2 - 4 } & Widow & 0 & 0.0 \\
\hline
\end{tabular}

Table no-3 shows that the majority of the respondents $96 \%$ were married, while $4 \%$ respondents were single and $0 \%$ respondents were widow.

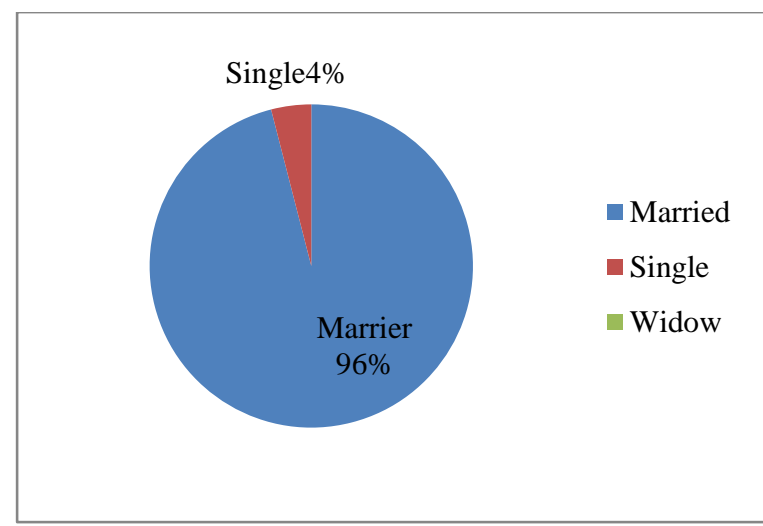

Fig-3: Marital status of the respondents

Table-4: Distribution of Religion of the respondents

\begin{tabular}{|l|l|l|l|}
\hline variable & Parameter & Number & Percentage \\
\hline Religion & Muslim & 35 & 70.0 \\
\cline { 2 - 4 } & Hindu & 11 & 22.0 \\
\cline { 2 - 4 } & Christian & 4 & 8.0 \\
\hline & Buddhist & 0 & 0.0 \\
\hline
\end{tabular}

Table 4.shows that maximum number of nurse's respondents $70 \%$ was Muslim, while $22 \%$ were Hindu and $8 \%$ were Christian in $\mathrm{RMCH}$.

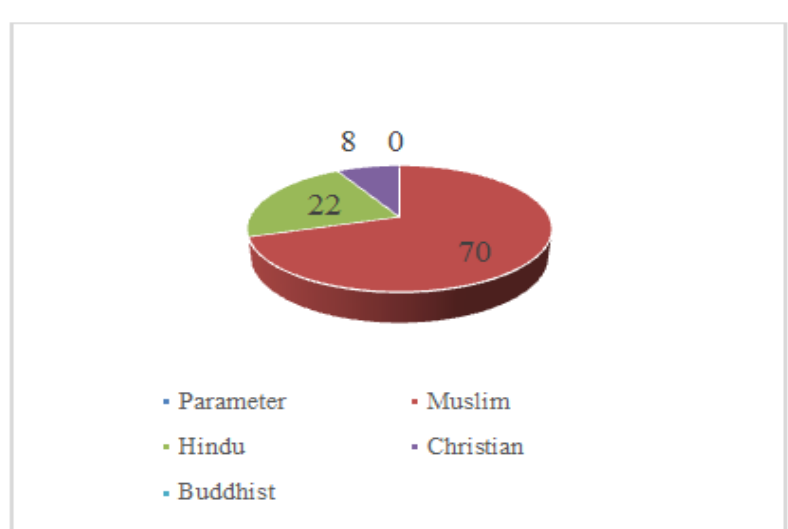

Fig-4: Distribution of Religion of the respondents

Table-5: Academic qualification of the respondents

\begin{tabular}{|l|l|l|l|}
\hline Variable & Degree & Number & Percentage \\
\hline \multirow{2}{*}{$\begin{array}{l}\text { Academic } \\
\text { Qualification }\end{array}$} & S.S.C. & 45 & $90 \%$ \\
\cline { 2 - 4 } & H.S.C & 5 & $10 \%$ \\
\cline { 2 - 4 } & B.Sc./B.A & 1 & $2 \%$ \\
\hline
\end{tabular}

Table- 5 shows that the majority of staff nurse respondents $90 \%$ having S.S.C only, while $10 \%$ have H.S.C. only and $2 \%$ have B.SclBA degree. 


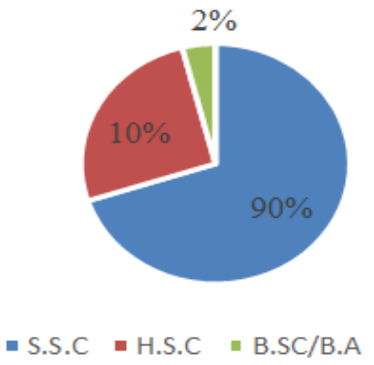

Fig-5: Academic qualification of the respondents.

Table-6: Professional qualification of the respondents

\begin{tabular}{|l|l|l|l|}
\hline Variable & Degree & Number & percentage \\
\hline Professional & $\begin{array}{l}\text { Diploma in } \\
\text { nursing }\end{array}$ & 38 & $96.0 \%$ \\
\hline qualification & B.Sc in nursing & 12 & $24.0 \%$ \\
\hline & Mph/M.sc & 3 & $6.0 \%$ \\
\hline
\end{tabular}

Table 6 shows that the majority of staff nurse respondents $96 \%$, having diploma in nursing and midwifery only and $24 \%$ have B. Sc in Nursing and 06\% have MPH/M.Sc Degree.

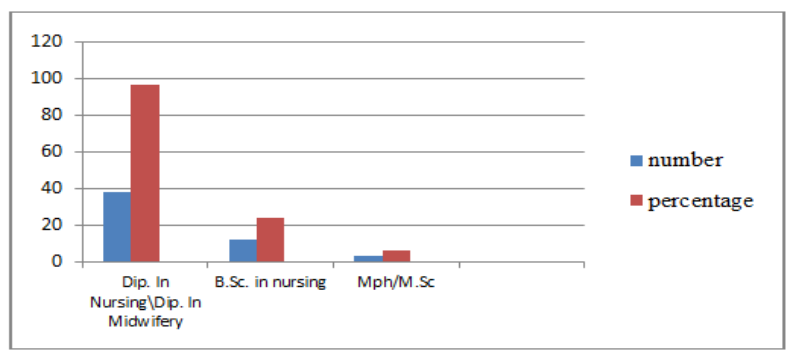

Fig-6: Professional qualification of the respondents.

Table-7: Length of service of the respondents.

\begin{tabular}{|l|l|l|l|}
\hline Variable & Range & Number & Percentage \\
\hline Length of & 1-10 year & 25 & 50.0 \\
\hline Service & 11-20 year & 25 & 50.0 \\
\hline & 21-30 year & 0 & 0.0 \\
\hline
\end{tabular}

Table 7 shows that majority of staff nurse $0 \%$ respondents had age of their length service between the years $21-30$ and 50\% nurses are serving from $1-10$ years, $50 \%$ were within the $11-20$ years.

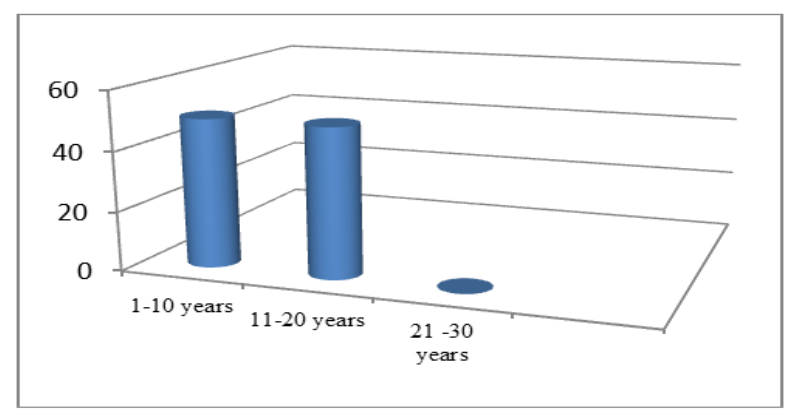

Fig-7: Length of service of the respondents
The assumption is that ergonomically designed shift schedules will assist in the reduction of physiological and psychosocial hazards in the workplace [8]. The focus of this study is directed towards consideration of human factors in the design of night shift for the nurses. The study was conducted in Rajshahi Medical College Hospital, Rajshahi, Bangladesh. The most of the respondents age within 2630 years $6(12 \%), 31-35$ year $15(30 \%), 36-40$ year $18(36 \%)$ the lowest group respondent age within $41-45$ year $25(50 \%)$. The gender of the respondents are the height number are $46(92 \%)$ female and the lowest number are 2(4\%) male. The marital status of the total respondents are 50, most of the (48) $96 \%$ are married, 2 (4\%) single and $0 \%$ widow. The major study involved in this hospital whereby nursing personnel were required to respond to a questionnaire directed to the nurses working at night shift. Studies show that shift workers accident rates are more than day workers [9]. Thus the findings do not conclusively indicate that night shift workers are more prone to accidents. There are also discrepancies with research on this issue because of the fact that working conditions are not the same on different shifts. The total religion of the respondents are 50, most of them were Muslim 35 (70) \%, Hindu11 (22\%) and Christian 4(8\%) Buddist 0\%. Among 50 nurses Professional qualification of the respondents(38) $76 \%$ Diploma in Nursing and Midwifery in Nursing, (12) $24 \%$ B.Sc. in Nursing and MPH-3 (6\%).Among 50 nurses Academic qualification of the respondent S.S.C45 (90\%), H.S.C-5 (10\%), B.Sc./B.A-1 (2\%). B. Masers $0 \%$ and other $0 \%$. Specialization course on ICU nursing $\&$ management $8(16 \%)$ and CCU nursing \& management respectably. For example, the nature of workload, the backup system available, and the amount of supervision can make comparisons inaccurate. Nonetheless, lack of sleep heightens the decline in performance. Research has shown that the optimum mental performance level for workers occurs between 2-4pm, maximum general awareness is between 1-7pm. Performance levels are lowest between 3:30-5:30am 10,11]. Hospital personnel comprises of a multidisciplinary medical team, nurses with differ qualifications, administration staff and housekeeping personnel. The services provided include Medical care, surgical care, Paediatric care, Dental, Obstetrical and Gynaecological care and Operation theatre. The result indicated significant association between working on night shift and use of alcoholic beverages to help induce sleep. Moreover, average hours of sleep were significantly associated with three related sleep items: subjective sleep quality, difficulty in getting to sleep and daytime drowsiness $[12,13]$. In view of the above workforce and their assignment to different shift schedules within the health service, it was necessary to conduct this research to determine the impact and effects of night shift schedules on nurses. The night shift worker is a man at odds with his own body rhythms as stated by Perkins [14]. When managers are 
Tanzina Islam et al; Sch J App Med Sci, Mar, 2021; 9(3): 393-397

planning shift schedules should be aware of these biological rhythms as explained by other researchs. Literature has explained that there is no perfect schedule; the main factor is consideration of the inputs from the participants in shift work. Shift work environment should be comfortable, safe and free from hazards such long hours at work. The study should be able to give direction as to what steps should be taken to protect nurses from the occupational stress caused by night shift. The study was conducted in specific wardcardiology wards (ICU-Intensive Care Units, PCCUPost Coronary Care Units), paediatrics wards, gynaecology-department, post-operative wards, medicine and surgery wards and neurology ward. About the prevalence of extended work periods and their effects on patient safety. Logbooks completed by 393 hospital staff nurses revealed that participants usually worked longer than scheduled and that approximately 40 percent of the 5,317 work shifts they logged exceeded twelve hours. The risks of making an error were significantly increased when work shifts were longer than twelve hours, when nurses worked overtime, or when they worked more than forty hours per week [15].

\section{CONCLUSION}

Shift work is an essential feature of modern society. Shift work, especially at night, has been associated in the literature with four main problems: difficulty with day sleeping and therefore greater levels of fatigue and sleepiness both on and off the job; an increased risk for accidents and errors at work and after work; an increased likelihood of health and well-being problems; and increased social and domestic difficulties Study shows that all age groups are subject to exposure to physiological and psychological hazards brought about by night shift as indicated in their subjective response. The recent developments regarding shift work is aimed towards improvement of health of shift workers, the physical and psychosocial well being as stated by International Labor Office ILO. ILO has highlighted that recommendation should be relevant to specific groups and work systems; each sector has its own specific needs, especially health sector as it deals with patient care. Further studies are required to find out the extent of night shift effect. Management wills benefits with further research in this area. The purpose of this study to describe hazards affecting nurses working on night shift and to make recommendations based on the finding. It has been noted from previous studies that night workers sleep about 1 hour less than day workers, and that night workers' sleep has "poor quality". Night workers accumulate a sleep deficit and sleepy workers make mistakes. The most dangerous are those who build up a "sleep debt" depriving themselves of sleep over long periods. Human body does not function well without proper sleep. This happens because the body's functions are controlled by the circadian rhythms. This rhythm is the biological pattern that tells us to sleep at night, and be active by day.

\section{REFERENCES}

1. Åkerstedt T, Gillberg M. Subjective and objective sleepiness in the active individual. International Journal of Neuroscience. 1990 Jan 1;52(1-2):29-37.

2. Åkerstedt T. Sleepiness as a consequence of shift work. Sleep. 1988 Jan 1;11(1):17-34.

3. August- Brady M. Prevention as intervention. Journal of Advanced Nursing. 2000 Jun;31(6):1304-8.

4. Bohle P, Tilley AJ. The impact of night work on psychological well-being. Ergonomics. 1989 Sep 1;32(9):1089-99.

5. Lushington $\mathrm{W}$, Lushington $\mathrm{K}$, Dawson D. The perceived social and domestic consequences of shiftwork for female shiftworkers (nurses) and their partners. Journal of occupational health and safety Australia and New Zealand. 1997;13:461-70.

6. Lushington $\mathrm{W}$, Lushington $\mathrm{K}$, Dawson D. The perceived social and domestic consequences of shiftwork for female shiftworkers (nurses) and their partners. Journal of occupational health and safety Australia and New Zealand. 1997;13:461-70.

7. Bohle P, Tilley AJ. The impact of night work on psychological well-being. Ergonomics. 1989 Sep 1;32(9):1089-99.

8. Allen C. Summary of the Crost Seminar: shift work retrieves from Oregon Health and Science University on March/10/2004 website httpi.

9. Bohle P, Tilley AJ. The impact of night work on psychological well-being. Ergonomics. 1989 Sep 1;32(9):1089-99.

10. Coffey LC, Skipper Jr JK, Jung FD. Nurses and shift work: effects on job performance and jobrelated stress. Journal of advanced nursing. 1988 Mar;13(2):245-54.

11. Coffey LC, Skipper Jr JK, Jung FD. Nurses and shift work: effects on job performance and jobrelated stress. Journal of advanced nursing. 1988 Mar;13(2):245-54.

12. Ohida T, Kamal AM, Sone T, Ishii T, Uchiyama M, Minowa M, Nozaki S. Night- shift work related problems in young female nurses in Japan. Journal of occupational health. 2001 May;43(3):150-6.

13. Ohida T, Kamal AM, Sone T, Ishii T, Uchiyama M, Minowa M, Nozaki S. Night- shift work related problems in young female nurses in Japan. Journal of occupational health. 2001 May;43(3):150-6.

14. Perkins LA. Is the night shift worth the risk? RN. 2001 Aug 1;64(8):65-.

15. Rogers AE, Hwang WT, Scott LD, Aiken LH, Dinges DF. The working hours of hospital staff nurses and patient safety. Health affairs. 2004 Jul;23(4):202-12. 